\title{
GIS-BASED INTEGRATED ANALYSIS FOR WATER RESOURCES VULNERABILITY: A CASE STUDY IN THE NORTH-WEST OF ITALY
}

\author{
ORNELLA SALIMBENE ${ }^{1}$, SALEM S. GHARBIA ${ }^{2} \&$ FRANCESCO PILLA $^{3}$ \\ ${ }^{1}$ Politecnico of Torino, Italy \\ ${ }^{2}$ Institute of Technology, Sligo \\ ${ }^{3}$ School of Architecture Planning and Environmental Policy of University College Dublin, Ireland
}

\begin{abstract}
This case study is an application of the integrated climatic modelling framework (GEO-CWB) in the metropolitan area of Torino (north Italy) for the projected period of 2080. The model was developed and validated at Trinity College of Dublin and uses Geographical Information System (GIS) as the climate change downscaling environment. The main goal of this research is to investigate the impacts of climate and land-use changes on the water resources vulnerability using GEO-CWB model with a wide range of input parameters and grids, including seasonal climate variables and changes, land use/land cover, seasonal parameters and future changes, seasonal groundwater depth, soil properties, topography and slope. An intense data collection activity was carried out for the year 2015, using all the possible sources available; additionally, potential evapotranspiration, as input data, was calculated using the method of Blaney-Criddle and modelled in GIS platform. In order to parametrize the hydrological response of the metropolitan area of Torino to the changes in climate and land use, GEO-CWB has a number of simulation stages (WBt) as follows: WBt stage (1) - dynamical water balance (DWB), WBt stage (2) - surface runoff iteration and WBt stage (3) - climate and land-use vulnerability parameters. As a result, GEO-CWB gives a wide range of seasonally and yearly gridded output layers as surface runoff, subsurface water, interception, evapotranspiration, soil evaporation, transpiration including total uncertainties or error in the water balance. GEO-CWB outputs could allow the scientific community, modelers, planners and decision makers to study the impact of climate and land-use changes on regional water resources vulnerability.

Keywords: climate change, GIS, north Italy, water balance, water vulnerability.
\end{abstract}

\section{INTRODUCTION}

Most assessments of global water resources have focused on surface water [1], but unsustainable depletion of groundwater has recently been documented on both regional [2] and global scales [3]. It remains unclear how the rate of global groundwater depletion compares to the rate of natural renewal and the supply needed to support ecosystems. It seems that the size of the global groundwater footprint is currently about 3.5 times the actual area of aquifers; that said, $80 \%$ of aquifers have a groundwater footprint that is less than their area, meaning that the net global value is driven by few overexploited aquifers. Groundwater occupies a considerable portion of the world's freshwater resources and is related to climate change via surface water such as rivers, lakes and marshes and direct interactions, being indirectly affected through recharge [4]. Modelling and assessing the impacts of climate change effects on water resources is a multistage process, which can be processed through several methods and techniques such as physically based models, statistically based models and machine learning methods $[5,6,7,8]$. Dynamical downscaling used by S.S. Gharbia for the GEOCWB model relies on the use of a regional climate model (RCM), similar to a GCM in its principles but with high resolution. RCMs take the large-scale atmospheric information supplied by GCM output at the lateral boundaries and incorporate more complex topography, the land-sea contrast, surface heterogeneities and detailed descriptions of physical processes in 
order to generate realistic climate information at a spatial resolution of $50 \mathrm{~km}$. Geographical Information System (GIS) is well suited for urban hydrology because of the strong spatial variability and fast dynamics of urban lands. Urban databases, with detailed and up-to-date information, are a precious source of information for hydrological statistic models [9], and this approach was followed for this case study in a city located in a sensitive area to climate change impact. In Italy, the water demands and threats to both surface water and groundwater resources have grown dramatically in recent years, fueled by the competing interests of urbanization, industrial development and tourism and compounding the threats now posed by climate change.

\section{STUDY AREA}

The study area considered in this research includes the metropolitan area of Turin $(239 \mathrm{~m}$ a.s.l.), a city in the north-west of Italy $\left(45^{\circ} 03^{\prime} \mathrm{N}, 7^{\circ} 40^{\prime} \mathrm{E}\right)$ in the Region of Piemonte. On the territory of the province of Turin weighs more than half of the population of the whole region and a high concentration of productive settlements; there are about 60,000 total wells, of which 15,000 for non-domestic uses and 3,000 derivations, 2,000 discharges and 15 concessions of mineral and thermal waters. The observations available and developed by Regional Agency for Environmental Protection of Piemonte (ARPAP, 2018) have shown an increase in temperatures of $1.5^{\circ} \mathrm{C}$ in the region over the last 60 years, in practice twice as much as the global average. Rainfall, however, did not change significantly although there is a weak statistical signal of an increase in 'extreme' events in recent years; in other words: longer drought periods alternating with more intense rain, all these aspects affect the regional water balance (WB) and the annual evapotranspiration (ET) processes. For this research, the monitoring area has been extended to $1,782 \mathrm{~km}^{2}$ in order to have as much information as possible; Fig. 1 shows the study area localization and all weather stations used for this study and managed by ARPA.

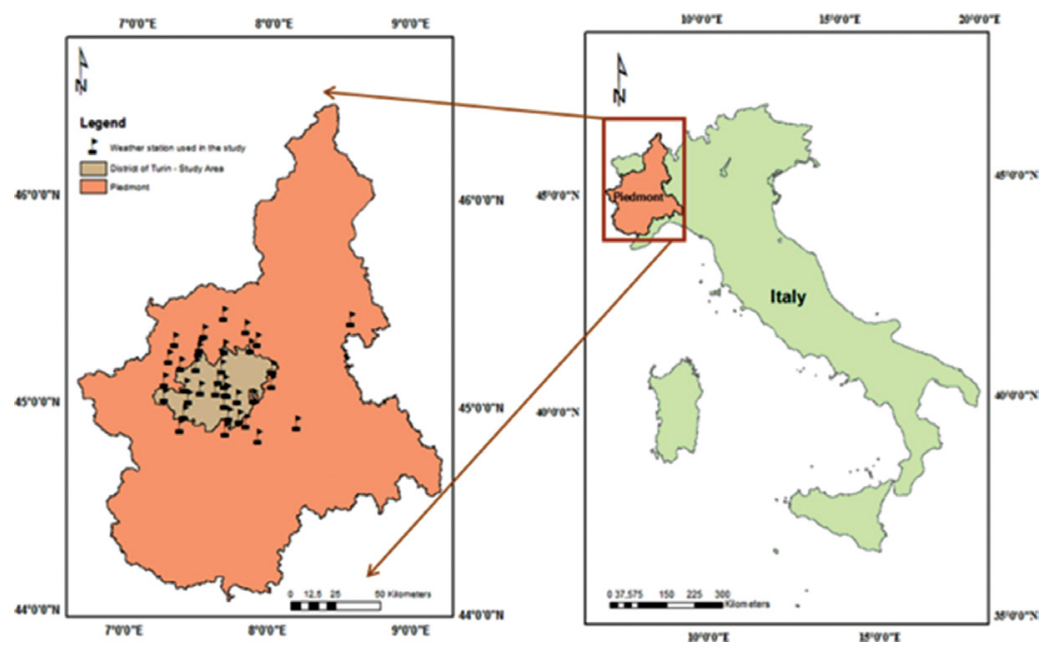

Figure 1: Localization of ARPA weather stations (Source: O. Salimbene, 2020). 


\section{INPUT DATA \& WBT MODEL}

GEO-CWB requires a wide range of input raster information; Table 1 shows all sources of data used in this research. In order to obtain geological information, several research institutes have been consulted: the Institute for Plants and the Environment (IPLA), the Hydrology and Natural Hazards Department of Forecasting Systems of ARPAP and the regional data archive of the Piemonte region (Italy).

The depth of a water table is influenced by seasonal fluctuations in fluvial weather, watercourse regime and intensive agricultural activity (pumping from wells and canal irrigation). A grid of depth of water table was obtained as the difference between the topographic grid and the grid of the piezometric level. This matrix was then displayed as a raster map to represent the groundwater level of the study area in accordance with winter and summer fluctuations. Furthermore, to best represent the hydrogeological conditions, for each type of soil, the porosity values were associated, as well from the literature.

Concerning meteorological and climatic data, 50 meteorological stations managed by ARPAP were considered. The 2015 results were found to be in the standard in terms of rainfall, but their peculiarities were an alternation of very rainy months with other ones characterized by warm weather and absence of precipitation. A moderate drought occurred between July and August, while, starting from November, there was a very prolonged dry period, ending at the beginning of 2016. The precipitations were scarce in January and starting from 29 October 2015; for the subsequent 97 consecutive days, never was observed a day with an average rainfall on the region exceeding $5 \mathrm{~mm}$. This extended period was one of the four longer registered in Piedmont in the last 60 years and comparable only to the April/May 1997 and February 1981. Therefore, this rare and particular situation has affected the water reserves available on the territory. The pluviometric anomaly has been going on for three years in the study area and was also recorded during the succeeding years 2017-2018. All the data described have been analyzed with GIS software; raster maps have been developed for each weather-climate parameter, and the same geostatistical analysis was carried out for the classification of the soil, slope and cover land. Regarding weather and climatic information, all the data have been processed to obtain geospatial maps as input data in GEO-CWB. For each parameter (wind, temperature, solar radiation, humidity and rainfall), 12 raster maps were produced, one for each month of the year 2015. It was necessary to apply deterministic interpolation techniques based on either the extent of similarity Inverse Distance Weighted (IDW) interpolation to obtain total

Table 1: Sources of data used in this research (O. Salimbene, 2020).

\begin{tabular}{ll}
\hline Data & Source \\
\hline Catchment and sub-catchment & AIPO - Interregional Agency for the Po River (Italy) \\
Hydrometric data & $\begin{array}{l}\text { ARPAP - Regional Agency for Environmental Protection } \\
\text { of Piemonte, To (Italy) }\end{array}$ \\
Meteorological data & $\begin{array}{l}\text { ARPAP - Regional Agency for Environmental Protection } \\
\text { of Piemonte, To (Italy) }\end{array}$ \\
Land-use and land-cover land & CORINE - Copernicus Land Monitoring Service (EU) \\
Soil data & Hydrology and Natural Hazards, ARPAP - To (Italy) \\
Topography & CORINE - Copernicus Land Monitoring Service (EU) \\
Ground water level & Regional Authority of Piemonte, To (Italy) \\
\hline
\end{tabular}


coverage across the study area. Additionally, GEO-CWB requires the spatial estimation of potential evapotranspiration (PET), and therefore, the Blaney-Criddle method for estimating was applied using eqn (1)

$$
\mathrm{PET}=k p\left(0.46 T_{A}+8.13\right)
$$

in which PET is ET in mm from a reference crop for the period corresponding to $p, T_{\mathrm{A}}$ is the mean temperature in ${ }^{\circ} \mathrm{C}$ for the same period, $p$ represents the percentage of total daytime hours for the period used (whether daily, weekly, monthly, etc.) out of total daytime hours of the year, i.e., $365 \times 12$, and $k$ is a monthly consumptive use coefficient [10], depending on vegetation type, location and season. Eqn (1) is most well known in the USA, but it has been used extensively elsewhere; Food and Agriculture Organization (FAO) of the United Nation temperature methodology recommended by Pruitt and Doorenbos, 1977, is based on the Blaney-Criddle method.

The GEO-CWB-modelled WB for the projected period of 2080 uses the ArcView GIS platform through a series of customized scripts. Therefore, the source code is a mix of GIS operations, implemented through the use of the python scripting language. The tool is implemented within an ad hoc ArcView project in which all the scripts, datasets and output are stored according to the predefined paths. The model simulates three different systems which are climate, land use and the hydrological system; the relationships between the three systems in the model need to be multidimensional as a flexible two-way simulation iterations process. Statistically based models and machine learning techniques in the design of the GEO-CWB have been used in the fine-scale resolution downscaling for climate simulations [11]. Statistically based models have been used widely in addressing complicated hydrological problems $[12,13,14]$. Figure 2 shows the flowchart of GEO-CWB, the input data required, the three work stages and all output projections of simulation.

During the processing stages, the physically based algorithm designed for GEO-CWB (Pixelated Cubical Balance Approach) works in the following direction: it suggests dividing the model extent into small cubes (the higher the number of cubes, the higher the accuracy), with each small cube having its own simulation process, which happens within the same time scale and allows the linkage between the physically and statistically based models. GEO-CWB simulates water balance (WBt) for each single cell as is summarized in the following equation:

$$
P_{\text {cell }}=E T_{C E L L}+S_{C E L L}+R_{C E L L}+I_{C E L L}
$$
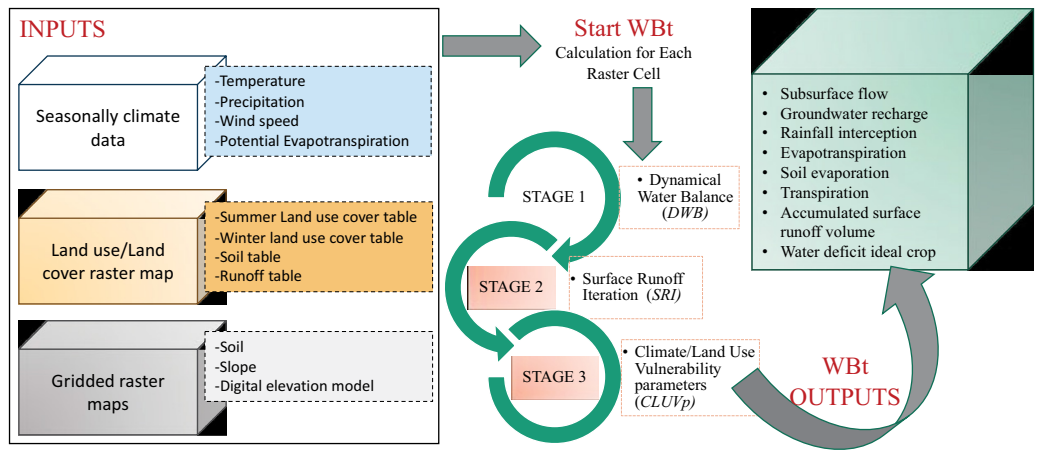

Figure 2: Flowchart of GEO-CWB (Source: S.S. Gharbia, adapted by O. Salimbene, 2020). 
where $P_{\text {cell }}$ represents the precipitation component, $R_{\text {cell }}$ is the subsurface water component, $S_{\text {cell }}$ is the surface water component, $E t_{\text {cell }}$ is the evapotranspiration and $I_{\text {cell }}$ is the interception component. Each single pixel in the domain in each time step runs through the GEO-CWBdesigned algorithm, using the input rasterized datasets as following: land use (raster maps), precipitation (raster maps), PET (raster maps), wind speed (raster maps), temperature (raster maps), groundwater level (raster maps), soil texture (raster maps), slope, DEM raster, topography, average porosity (as a single value) or average porosity (raster map).

\section{APPLICATION AND RESULTS}

The aim of the study is to apply GEO-CWB to calculate all the components of the WB projected to 2080. To simplify all output projections, the results have been organized into two seasonal semesters as following: summer and winter WB for the projected period 2080. GEO-CWB processed the results in three stages divided into: WBT stage (1) - dynamical water balance (DWB); WBT stage (2) -surface runoff iteration (SRI); and WBT stage (3) climate and land-use vulnerability parameters (CLUVp).

\subsection{WBt simulation stage (1) - DWB}

At this stage, the individual dynamical pixel WB is calculated by summing up the independent pixel's subdivision-simulated WB. Depending on the land-use type assigned to each pixel, the tool divides the upper pixel's surface into vegetated area, bare soil area, open waterbodies and impervious area. This section shows the simulated annual, summer and winter WB variables and components for the study area. The annual average and the seasonal surface runoff maps simulated by GEO-CWB are shown in Fig. 3(a) that represents the mean winter and summer surface runoff for the combinations and interactions of land-use and soil classes. The largest surface runoff occurs on the soil group with wetlands and in urbanized areas (the yellow area in Fig. 3(a) is the most urbanized area and represents the extension of Turin city) with largest annual value of $76.68 \mathrm{~mm}$, while the lowest values are for the soil group with agricultural areas. The traceability of the soil-type boundaries and the higher standard deviation values of the runoff for different soil groups show that the surface runoff is more influenced by soil type than by land use.

Also, it is noticeable that both winter and summer runoff profiles are different, but in this simulation, the data of the year 2015 are used, a year mainly dry during the autumn-winter season and with great rainfall during spring-summer. This explains the difference between the values of the winter and summer runoff projections and highlights how extreme events due to climate change abnormally affect the seasonal runoff. Each single pixel in the domain in each time step runs through the GEO-CWB-designed algorithm, using the input rasterized datasets as following: land use (raster maps), precipitation (raster maps), PET (raster maps), wind speed (raster maps), temperature (raster maps), groundwater level (raster maps), soil texture (raster maps), slope, DEM raster, topography, DEM raster, average porosity (as a single value) or average porosity (raster map).

\subsection{WBt simulation stage (2) - SRI}

The main aim of this stage is to recalculate the subsurface water component and surface runoff maps by iterating the groundwater depth variable. The inputs at this stage will be the output from the first-stage $D W B$ and the outputs will be the same variables, but after the 
iteration, all the outputs will have the number 2 in the file name to indicate that this file is the final map for this parameter, which has resulted from stage (2); specifically, the outputs are spatially distributed groundwater recharge (GWR), subsurface flow (SSF), rainfall interception (RI), ET, soil evaporation (SE) and transpiration (TR), and all maximum values for winter and summer are summarized in Table 2.

Based on that and according to data availability, at this stage, GEO-CWB calculates the subsurface water component which includes SSF and GWR; however, the model has the framework setup to separate the two main components, SSF and GWR, once the spatially distributed data for the recharge caps are available. GWR is concerned with the percolation of water through the soil, subsoil and down through the unsaturated zone to the water table $[4,15]$. GEO-CWB provides the framework of a cell-by-cell multidimensional dynamical GWR calculation for the catchment scale by applying the WB calculation for each cell's subfraction, which provides a high-accuracy simulation compared with the currently used approaches, when the spatially distributed recharge data are available. GWR in the study area (Fig. 3(b)) and anywhere else is promoted by low ET and low surface runoff; e.g., typically for a flat topography and permeable soils, the maximum of average annual recharge projected value is $126.51 \mathrm{~mm}$ as shown in Table 2. In the north-west of Italy, the water demands and threats to both surface water and groundwater resources have grown dramatically in recent years, fueled by the competing interests of urbanization, industrial development and tourism and compounding the threats now posed by climate change. As mentioned in Section 2, the study area weighs more than half of the population of the whole region and a high concentration of productive settlements; there are about 60,000 total wells, of which 15,000 for nondomestic uses and 3,000 derivations, 2,000 discharges and 15 concessions of mineral and thermal waters; furthermore, the disparity between demand and supply is likely to increase with climate change. SSF components depend strongly on the percentage of soil waterproofing; Fig. 3(c) gives the mean annual SSF subsurface water component values for different combinations and interactions of land use and soil classes. The largest SSF component is observed for the area with the relatively gentler slopes with a maximum annual average value of $72.68 \mathrm{~mm}$. RI is the fraction of precipitation which falls into vegetation but never reaches the ground, instead of evaporating from the wet canopy. The model calculates the RI as a direct fraction of precipitation, separated from the ET, which means the total water lost from the precipitation in the catchment can be calculated by the sum of both ET and interception.

Table 2: WBt simulation stage (2) - SRI water balance components, max values in [mm] for the projected period 2080, (Source: O. Salimbene, 2020).

\begin{tabular}{lllll}
\hline $\begin{array}{l}\text { WBt stage (2) - SRI } \\
\Rightarrow 2080\end{array}$ & & $\begin{array}{l}\text { Annual } \\
{[\mathrm{mm}]}\end{array}$ & $\begin{array}{l}\text { Winter } \\
{[\mathrm{mm}]}\end{array}$ & $\begin{array}{l}\text { Summer } \\
{[\mathrm{mm}]}\end{array}$ \\
\hline Water balance components & Fig. 3 & Max value & & \\
GWR & (b) & 126.51 & 57.59 & 97.56 \\
SSF & (c) & 72.68 & 21.86 & 50.82 \\
RI & (d) & 65.68 & 17.01 & 48.67 \\
ET & (e) & Five subclasses & \\
SE & (f) & 31.11 & 14.83 & 16.03 \\
TR & (g) & 36.05 & 17.57 & 18.48 \\
\hline
\end{tabular}


The annual and seasonal averages spatially distributed maps for the projected period 2080 are shown in Fig. 3(d). The most vegetated areas to the north-west have greater interception values $(65.68 \mathrm{~mm})$, as well as the areas in the south-east of Po River which is covered by the city park of Valentino. GEO-CWB calculates the ET and RI components (open water fraction and vegetated fraction) individually which means that the total water loses from precipitation in the catchment is the summation of the two components. Greater ET takes place during the summer season; this is obviously due to the unequal temporal distribution of the temperature during the winter season but also partly to the fact that the vegetation is less active in the winter season. The annual and seasonal averages spatially distributed ET maps for the projected period 2080 are shown in Fig. 3(e). Four classes of ET values were identified with a minimum value of $2.63 \mathrm{~mm}$ and a maximum value of $37.07 \mathrm{~mm}$ in vegetated area (northwest and Po Valley), where also soil evaporation simulation returns maximum values. Soil evaporation is the evaporation from open soil area as a fraction of each simulated pixel and forms part of the total ET. The annual and seasonal averages spatially distributed SE maps are shown in Fig. 3(f), and the maximum annual average value simulated for 2080 period is 31.11 $\mathrm{mm}$ and concerns the non-urbanized areas. Regarding transpiration, it is the vaporization of water, which is contained in plant tissues and that mainly occurs through the stem and leaf stomata. TR, like direct evaporation, depends on factors such as radiation, air temperature, air humidity and wind speed. In addition, the soil water content and the ability of the soil to conduct water upwards play a role. The length of the plant's root system also plays an important role in determining the transpiration rate, in addition to the vegetation type. The annual and seasonal spatially distributed average TR maps for the period 2080 are shown in Fig. 3(g); the higher values correspond precisely to the areas where there is an intense vegetated area (north-west) with annual maximum value of $36.06 \mathrm{~mm}$ and in the area of the city park of Valentino along the Po River. GEO-CWB calculates also the error/change in storage fraction in each simulated cell WB, which provides an error/change in storage in WB for each simulated time step in each simulated climatic scenario. The small error/change in storage in the WB comes from the assumption that waterbodies can always evaporate at PET rate. Hence, this error should be subtracted from the runoff as open waterbodies are supplied by runoff from surrounding areas and does not leave the basin as river flow but are evaporated instead.

\subsection{WBt simulation stage (3) - CLUVp}

The WBt model produces some parameters from which an assessment can be made of the vulnerability to climate and land-use changes as follows: Accumulated Surface Runoff Volume (ASRV), the Safe Yield Groundwater Abstraction (SYGA) and the Water Deficit for Ideal Crop (WDIC). ASRV volume in the rainy season is an indication of how much runoff water could be harvested every year during the rainy season. The calculated accumulated runoff volume, as a result of the different climate change conditions and land-use scenarios, has significant evidence of high values in the cemented areas $\left(>100 \times 10^{6}\left[\mathrm{~m}^{3}\right]\right)$.

Regarding SYGA rates calculated by GEO-CWB, they could be used as an indication and a rough estimate of how much groundwater can be abstracted in a sustainable way without depleting the groundwater resources; the maximum annual value projected for the 2080 period is $0.83 \mathrm{~m}^{3} / \mathrm{day} / \mathrm{h}$ calculated as a result of the different climate change conditions and land-use scenarios. The areas most sensitive to the impact of climate change are where there is already an overexploitation of water resources; on the whole, GEO-CWB simulates the absence of water deficit for ideal crop for the green areas close to the mountain (north-west) 
(a) WBt stage (1) - DWB
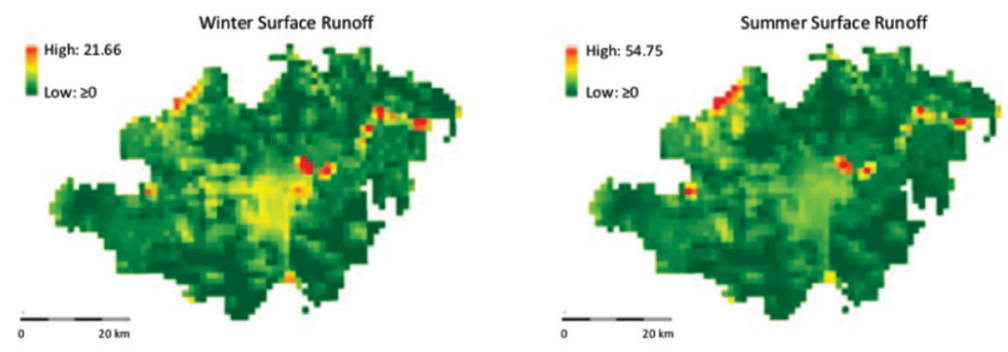

(b) WBt Simulation stage (2) - SRI/ GWR
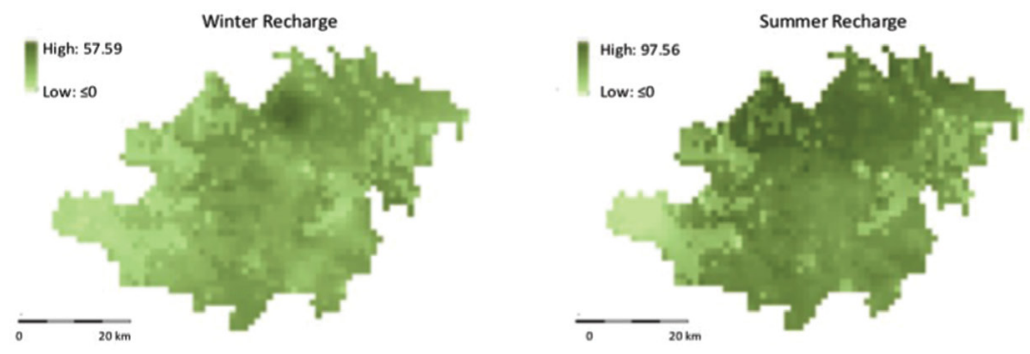

(c) WBt Simulation stage (2) - SRI/ SSF
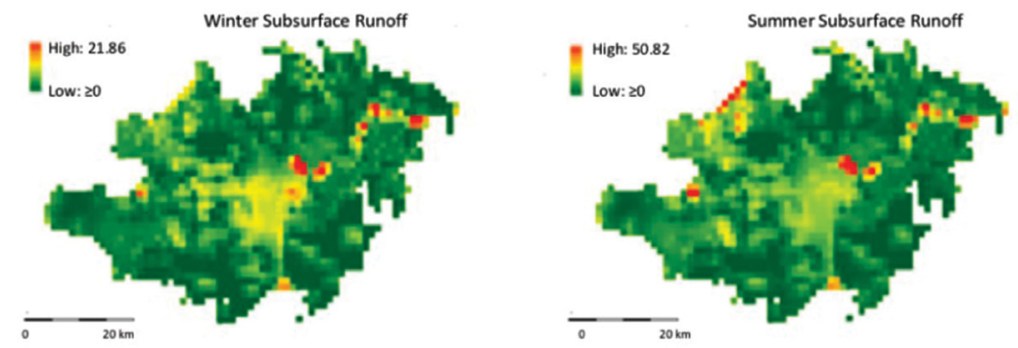

(d) WBt Simulation stage (2) - SRI-RI
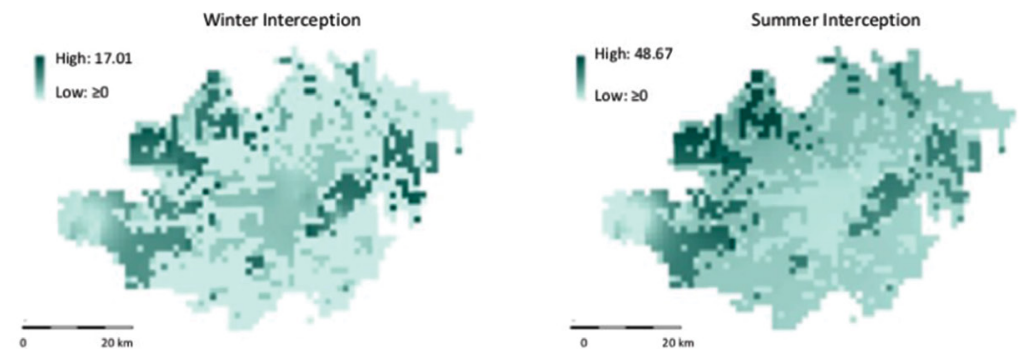

Figure 3: (Continued) 
(e) WBt Simulation stage (2) - SRI-ET
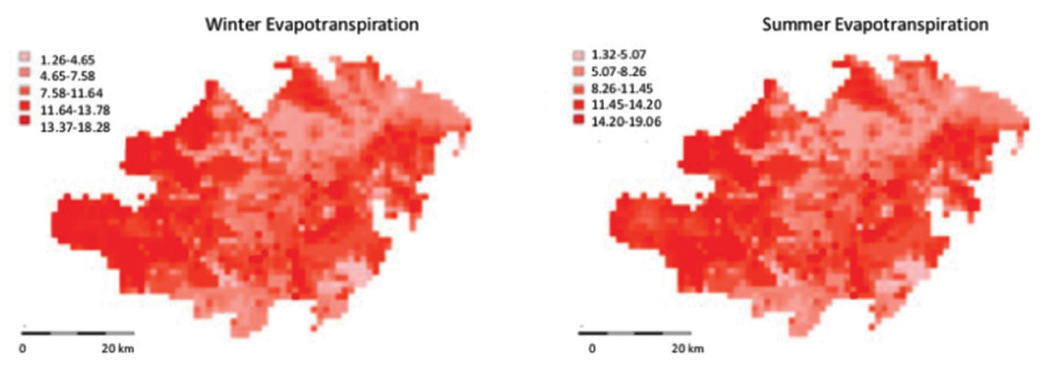

(f) WBt Simulation stage (2) - SRI-SE


(g) WBt Simulation stage (2) - SRI-TR
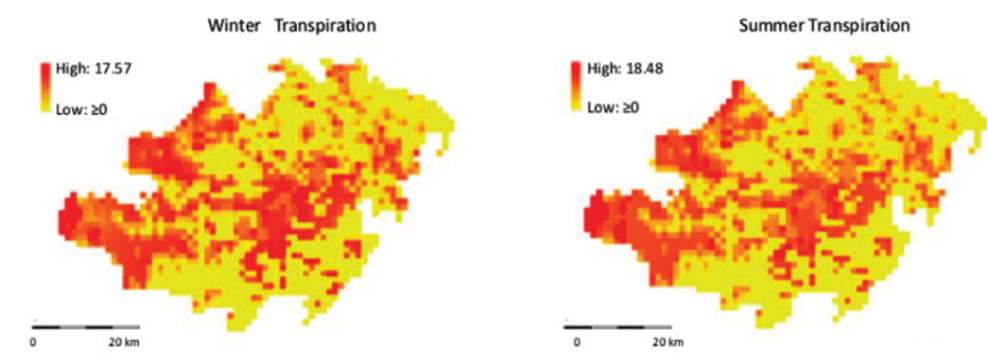

Figure 3: WBt simulation stage (1) \& stage (2), output simulations for the projected period 2080. (a) WBt stage (1) - DWB, (b) WBt simulation stage (2) - SRI/GWR, (c) WBt simulation stage (2) - SRI/ SSF, (d) WBt simulation stage (2) - SRI-RI, (e) WBt simulation stage (2) - SRI-ET, (f) WBt simulation stage (2) - SRI-SE and (g) WBt simulation stage (2) - SRI-TR (Source: O. Salimbene, 2020).

and a little possible deficits $[1.9 \mathrm{~mm}]$ in the most cementated area with a maximum in the area covered by airport and industrial area. WDIC growth can be estimated as the difference between the crop water requirement and the real ET.

At the end of the stages and simulations, the model returns the statistical parameters related to the WB calculated according to the equation of $W B$ :

$$
W B=P-R_{O}-E_{T}-R_{E}[m m]
$$


Table 3: WBt simulation stage (3) - CLUVp water balance components, maximum values in for the projected period 2080, (Source: O. Salimbene et al., 2020).

\begin{tabular}{llll}
\hline $\begin{array}{l}\text { WBt stage }(3)-C L U V p \\
\Rightarrow 2080\end{array}$ & Annual & Winter & Summer \\
\hline & \multicolumn{2}{l}{ Max value } \\
ASRV $\left[N \times 10^{6} \mathrm{~m}^{3}\right]$ & $>100$ urban areas and airport areas & \\
SYGA $\left[\mathrm{m}^{3} / \mathrm{day} / \mathrm{h}\right]$ & 0.86 & 0.2 & 0.66 \\
WDIC $[\mathrm{mm}]$ & 1.9 & 0.9 & 1.03 \\
\hline
\end{tabular}

Table 4: Water balance for 2080 projected period, Ro = runoff, $\mathrm{E}_{\mathrm{T}}=$ evapotranspiration, $\mathrm{Se}=$ soil evaporation, $\mathrm{In}=$ interception, $\mathrm{Tr}=$ transpiration, $\mathrm{Re}=$ subsurface water component, $\mathrm{P}=$ precipitation; SDT = standard deviation, (Source: O. Salimbene, 2020).

\begin{tabular}{lllllll}
\hline Ro $[\mathrm{mm}]$ & $\mathrm{E}_{\mathrm{T}}[\mathrm{mm}]$ & $\mathrm{Se}[\mathrm{mm}]$ & $\mathrm{In}[\mathrm{mm}]$ & $\operatorname{Tr}[\mathrm{mm}]$ & $\operatorname{Re}[\mathrm{mm}]$ & $\mathrm{P}[\mathrm{mm}]$ \\
\hline $9.24 \pm 5.1 \mathrm{SDT}$ & $18.52 \pm$ & $10.35 \pm$ & $16.62 \pm$ & $7.8 \pm$ & $63.25 \pm$ & 73.78 \\
& $7.64 \mathrm{SDT}$ & $7.11 \mathrm{SDT}$ & $11.6 \mathrm{SDT}$ & $4.2 \mathrm{SDT}$ & $25.57 \mathrm{STD}$ & \\
& $\mathrm{Wb}=\mathrm{P}-\mathrm{Ro}-\mathrm{Et}-\mathrm{Re}=-17 \%$ & & & $\mathrm{CBe}=\mathrm{WB} / \mathrm{P}=-23 \%$ \\
\hline
\end{tabular}

in which $R_{O}$ is the runoff, $E_{T}$ is the evapotranspiration and $R_{E}$ is the subsurface component. Table 4 summarizes all values and the final results of WB projected for 2080 period $(W B=-17.23 \%)$ and the annual error of WB ( $W B e=-23 \%)$.

The results show that the urbanized and cemented areas greatly influence the ET capacity of the soil; indeed, these areas also present the lowest ET and interception values. The maximum transpiration values fall in all the most vegetated areas (in the north-west of the study area) and close to the river Po whose banks are largely covered by a rich vegetation and the central core of the Turin city is flanked by a large urban park. The most vulnerable areas concerning the extraction of groundwater are just those next to the urban nucleus, probably already overexploited in previous years.

\section{CONCLUSION}

The Regional Authority of Piemonte has dedicated efforts and resources to expand the status of the knowledge on the situation of the water on its territory, with the aim of safeguarding its availability and quality. Over time, it has developed a management model-integrated resource, which involves and enhances the most significant experiences at local level. The GEO-CWB model could help and support water sector modelers, planners and decision makers to simulate and predict future spatially distributed dynamic WBs using a GIS environment at local scale [11]. Through the model, it is possible to test any assumed or planned future scenarios and to quantify their impacts and intrinsic uncertainties related to different components making up the catchment WB. GEO-CWB operates on a GIS platform, and thus, its results could be used as inputs for other GIS-related applications, such as drought and flood risk analysis and aquatic ecosystem applications in order to target areas for enforcement of environmental 
regulations $[16,17]$. The research presents an integrated case study assessment of the impacts of climate and land-use changes using the model with a wide range of input parameters and grids, including seasonal climate variables and changes, land-use/land-cover and its seasonal parameters and future changes, seasonal groundwater depth, soil properties, topography and slope. Additionally, GEO-CWB presents three main advantages: (i) the ability to work with multidimensional files and phenomena, (ii) the ability to reuse the output from the model as inputs for other impact models because of the flexibility with the file formats and (iii) providing a simple user-friendly interface for such a complicated tool [18].

\section{ACKNOWLEDGMENTS}

We thank Davide Tiranti from ARPAP, Salvatore Morreale from ITHACA Research Center and Fabio Petrella from IPLA Institute for Plant and Environment (IPLA) for helpful discussions, comments and data support.

\section{REFERENCES}

[1] Siebert, S., Burke, J., Faures, J.M., Frenken, J., Hoogeveen, K., Döll, K. \& Portmann, F.T., Groundwater use for irrigation - a global inventory. Hydrology and Earth Systems Science, 14, pp. 1863-1880, 2010.

[2] Rodell, M., Velicogna, I. \& Famiglietti, J.S., Satellite-based estimates of groundwater depletion in India. Nature, 460, pp. 999-1002, 2009.

[3] Gleeson, T., Wada, Y., Bierkens, M.F. \& Van Beek, L.P., Water balance of global aquifers revealed by groundwater footprint. Nature, 488(7410), pp. 197-200, 2012.

[4] Misstear, B., Brown, L. \& Johnston, P., Estimation of groundwater recharge in a major sand and gravel aquifer in Ireland using multiple approaches. Hydrogeology Journal, 17, pp. 693-706, 2009 (a).

[5] Berkhout, F., Hertin, J. \& Jordan, A., Socio-economic futures in climate change impact assessment: using scenarios as 'learning machines'. https://doi.org/10.1016/S09593780(02)00006-7; 2002.

[6] Grotch, S.L. \& MacCracken, M.C., The use of general circulation models to predict regional climatic change. United States: N. p., Web. doi:10.1175/15200442(1991)004<0286:TUOGCM>2.0.CO;2; 1991.

[7] Kim, T.W. \& Valdes, J.B., Nonlinear model for drought forecasting based on a conjunction of wavelet transforms and neural networks. Journal of Hydrologic engineering, 8(6), 2003.

[8] Leavesley, G.H., Modeling the effects of climate change on water resources - a review. Climatic Change, 28, pp. 159-177, 1994.

[9] Bahremand, A. \& De Smedt F., Distributed hydrological modeling and sensitivity analysis in Torysa watershed, Slovakia. Water Resources Management, 22, pp. 393-408, 2008.

[10] Pruitt, W.O. \& Doorenbos, J., Empirical calibration - a requisite for evapotranspiration formulae based on daily or Longer Mean Climatic Data. International Round table Conference on Evapotranspiration, International Commission on Irrigation and Drainage, Budapest, Hungary, 1977.

[11] Gharbia, S.S., Gill, L., Johnston, P. \& Pilla F., Multi-GCM ensembles performance for climate projection on a GIS platform. Journal of Modeling Earth Systems and Environment, 2, pp. 1-21, 2016. 
[12] Agkun, A. \& Erkan, O., Landslide susceptibility mapping by geographical information system-based multivariate statistical and deterministic models: in an artificial reservoir area at Northern Turkey. Arabian Journal of Geosciences, 9(165), 2016.

[13] Müller M.F. \& Thompson, S.E., Comparing statistical and process-based flow duration curve models in ungauged basins and changing rain regimes. Hydrology and Earth Systems Science, 20, pp. 669-683, 2016.

[14] Wood, A.W., Leung, L.R., Sridhar, V. \& Lettenmaier, D.P., Hydrologic implications of dynamical and statistical approaches to downscaling climate model outputs. Climatic Change, 62, pp. 189-216, 2004.

[15] Misstear, B., Brown, L. \& Daly, D., A methodology for making initial estimates of groundwater recharge from groundwater vulnerability mapping. Hydrogeology Journal, 17, pp. 275-285, 2009 (b).

[16] Tague, C., Grant, G., Farrell, M., Choate, J. \& Jefferson A., Deep groundwater mediates streamflow response to climate warming in the Oregon Cascades. Climatic Change, 86, pp. 189-210, 2008.

[17] Chen, J., Brissette, F.P. \& Leconte, R., Uncertainty of downscaling method in quantifying the impact of climate change on hydrology. Journal of Hydrology, 401, pp. 190-202, 2011.

[18] Salem S.G., Gill, L., Johnston P. \& Pilla, F., GEO-CWB: GIS-based algorithms for parametrising the responses of catchment dynamic water balance regarding climate and land use changes. Hydrology, 7(3), pp. 39, 2020. https://ind01.safelinks.protection. outlook.com/?url=https\%3A\%2F\%2Fdoi.org\%2F10.3390\%2Fhydrology7030039\&a $\mathrm{mp} ;$ data $=02 \% 7 \mathrm{C} 01 \% 7 \mathrm{Csaranya}$.kumaresan\%40integra.co.in\%7C62b129f6db69403e8 9a008d82d9301ba\%7C70e2bc386b4b43a19821a49c0a744f3d\%7C0\%7C0\%7C63730 9456736367137\&amp;sdata=O1IPmbjP\%2FwWMnBIk1X\%2BLMH909tJMyazWg5 XXh0QNubo\%3D\&amp;reserved $=0$. 